\title{
"Dirigiu-se para a sede social da Elite Flor da Liberdade" e "ofereceu um banquete aos visitantes": sobre a variação de proposições em complementos verbais*
}

Rosane de Andrade Berlinck*

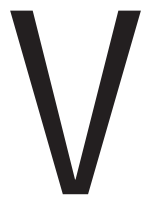

árias pesquisas têm constatado que as preposições em português, e, em particular, na variedade brasileira do português, estão sujeitas a processos que podem chegar ao apagamento, à substituição de preposições ou à especialização de sentidos (Tarallo, 1983; Castilho et al, 2002; Gomes, 2003, entre outros). Dada a relevância estrutural das preposições, responsáveis, em grande parte, pelo estabelecimento de relações sintáticosemânticas no nível da sentença, a investigação de tais processos se reveste de grande significação para o estudo da história da língua.

Os dois enunciados que compõem o título desse trabalho colhidos entre os dados que analisamos no presente estudo - ilustram 0 processo de variação no uso de preposições que é o foco dessa investigação: a alternância de preposições introdutoras de complementos que denotam um sentido geral de "meta", junto a predicadores verbais classificados, do ponto de vista sintático-semântico, segundo a tipologia proposta em Berlinck (1996). Os exemplos de (1) a (8) ilustram essas possibilidades:

\footnotetext{
0 presente estudo está inserido no Projeto Mudança gramatical no português de São Paulo: expressão pronominal e preposicional de argumentos, que integra o Projeto Para a História do Português Paulista Paulista (PHPP) (FAPESP - Proc. n 06/55944$0)$. Colaboraram nessa pesquisa as bolsistas de Iniciação Científica Letícia Cordeiro de Oliveira Bueno (PIBIC / CNPq) e Lívia Henrique de Albuquerque (PIBIC / CNPq).

* Docente da Universidade Estadual Paulista (UNESP-Araraquara/CNPq-Processo no. 305837 / 2007-9).
} 
(i) direção - predicadores que expressam como sentido prototípico a ideia de que ' $\mathrm{N}_{0}$ se move para $\mathrm{N}_{1}$ ', como ir, vir:

(1) Os comerciantes vieram á redacção relatar 0 fato.

(2) Quando o padeiro se dirigia para o estabelecimento onde trabalha, foi estupidamente atacado.

(ii) movimento com transferência - predicadores que expressam como sentido prototípico a ideia de que ' $\mathrm{N}_{0}$ move $\mathrm{N}_{1}$ para $\mathrm{N}_{2}$ ', como levar, trazer.

(3) Os amigos querem levá-lo para o Rio.

(4) Joana vai trazer seus amigos ao baile.

(iii) transferência material - predicadores que expressam como sentido prototípico a ideia de que ' $\mathrm{N}_{0}$ faz $\mathrm{N}_{1}$ ser possuído por $\mathrm{N}_{2}$ ', como dar, enviar :

(5) 0 polêmico projeto de lei foi mandado para o Senado.

(6) João ofereceu um lauto jantar aos convidados.

(iv) transferência verbal/perceptual - predicadores que expressam como sentido prototípico a ideia de que ' $N_{0}$ faz $N_{2}$ possuir um certo conhecimento, uma certa ideia ou uma certa percepção' como dizer, perguntar/mostrar.

(7) Maria declarou aos colegas que iria pedir demissão.

(8) Os produtores só vão mostrar documentários para o público do festival.

0 fenômeno de variação presente nos contextos mencionados não é uma característica que vamos encontrar apenas no estágio contemporâneo da língua. Um conjunto significativo de estudos já realizados permite estabelecer indícios de variação entre as preposições a, para e em, já em textos quinhentistas (Berlinck, 2006, 2007), que se intensifica em textos oitocentistas (Berlinck, 2000; Guedes \& Berlinck, 2003), e que, na verdade, sugere uma fase de completamento no estágio atual da língua (Berlinck, 1996, 1997, 1998, 2000, 2001; Gomes, 2003; Mollica, 1996; Torres-Morais \& Berlinck, 2006). Tais estudos revelam que há uma gradual diminuição no uso da preposição a nesses contextos, que vem sendo substituída pelas preposições para, em e até, com ênfase na primeira delas.

Dado esse quadro, o objetivo do presente estudo é buscar caracterizar os contextos pelos quais a preposição para começa a ocupar 0 espaço antes dominado pela preposição a. 0 u seja, pretende-se identificar 
em que construções 0 uso de para passa a constituir uma variante de a. Para isso, definimos um corpus de textos jornalísticos produzidos nas primeiras décadas do século XX, publicados na imprensa de São Paulo, que pertencem tanto à imprensa majoritária quanto à chamada "Imprensa Negra". Denomina-se tradicionalmente "Imprensa Negra" o conjunto de uma produção que tem início no período pós-abolição, produzida "por negros e para negros" (Ferrara, 1986; Domingues, 2006).

Os dados analisados provêm dos jornais: (i) O Estado de São Paulo - fundado ainda durante a Monarquia, em 1875, com o nome de A Província de São Paulo. É um dos jornais de maior longevidade no cenário jornalístico brasileiro e que sempre teve uma atuação muito importante no cenário político e social; (ii) O Combate, que circulou entre 1915 a 1930 e teve uma efetiva atuação no cenário social e político da cidade de São Paulo. Os exemplares que serviram de fonte para a análise correspondem às edições publicadas no ano de 1918; (iii) Getulino - jornal com periodicidade semanal, publicado em Campinas - SP, entre 1923 e 24 - faz parte do conjunto de periódicos que ficou conhecido como Imprensa Negra; e (iv) O Rio Claro - publicado na cidade de Rio Claro, interior de São Paulo, onde circulou de 1900 a 1916. Os exemplares estudados, ilustrados pelas figuras 1 a 4 a seguir, foram obtidos junto ao Arquivo Público do Estado de São Paulo e ao Arquivo Edgard Leuenroth - AEL (IFCH/UNICAMP).

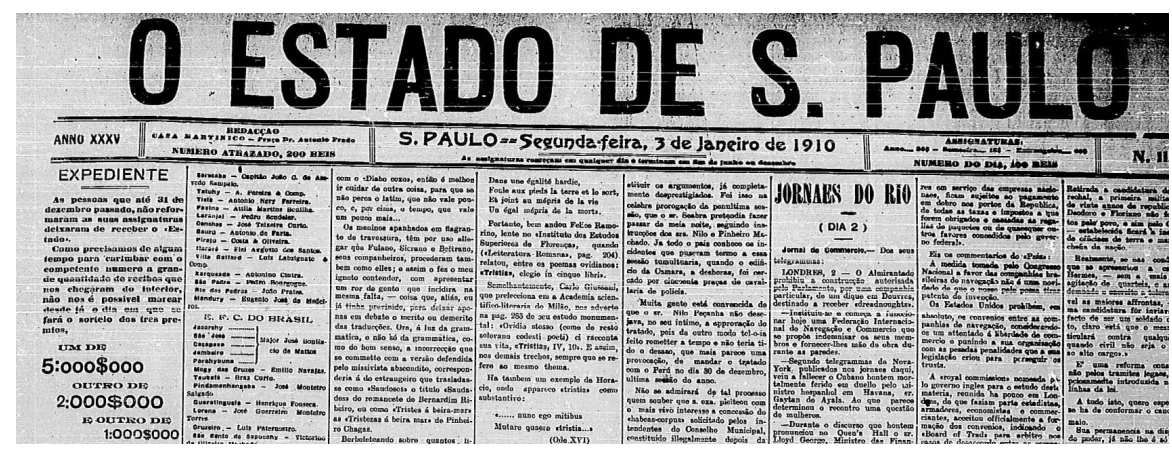

Figura 1. O Estado de S. Paulo, exemplar de 3 de janeiro de 1910 


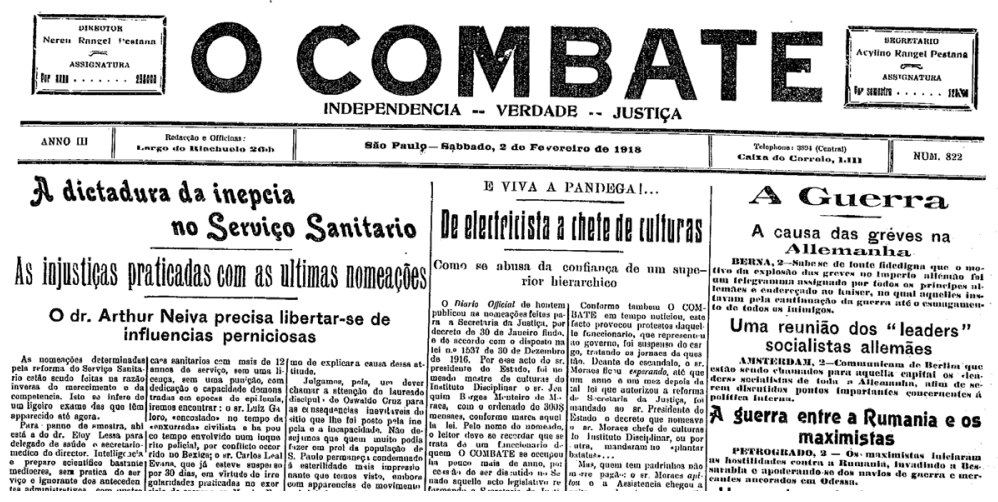

Figura 2. O Combate, exemplar de 2 de fevereiro de 1918

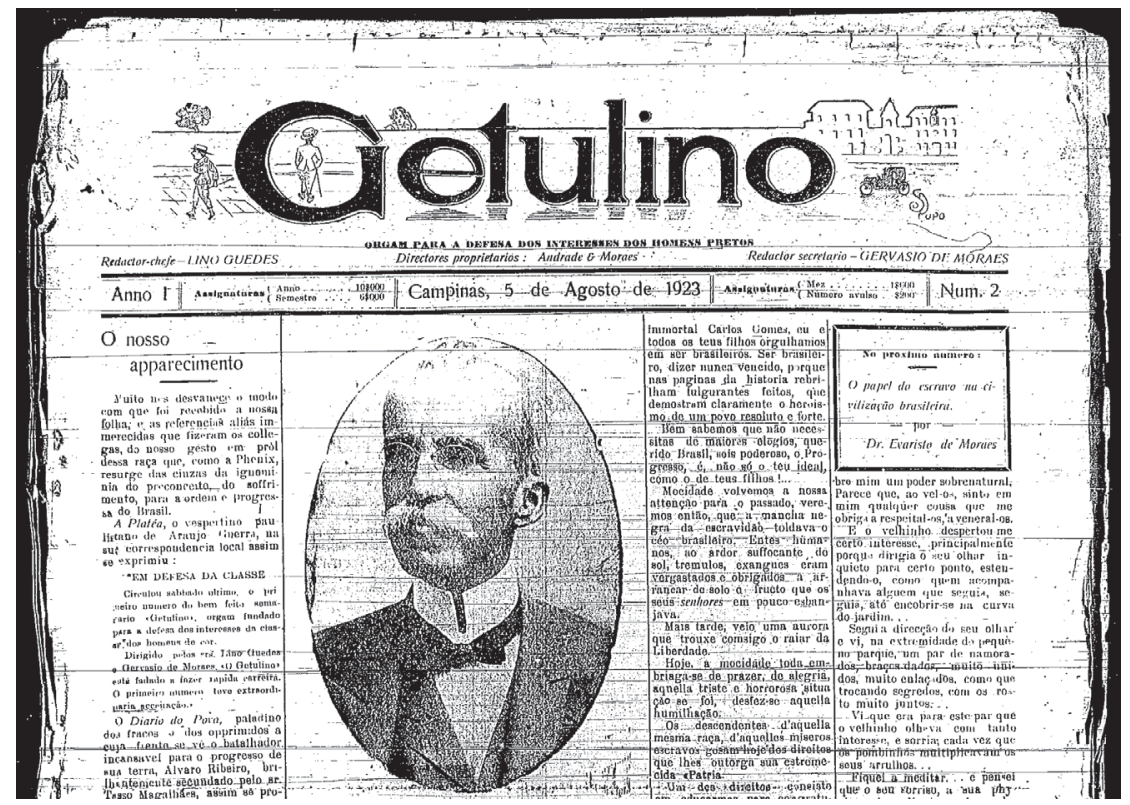

Figura 3. Getulino, exemplar de 5 de agosto de 1923 


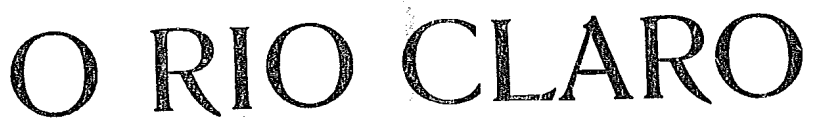

\begin{tabular}{|c|c|c|c|c|}
\hline S. PAU1, & $\mathrm{R} 10 \mathrm{Cl}$ & LARO, 3 DK JANEIRA D & DE 1015 & I. U. BRASIL NL \\
\hline 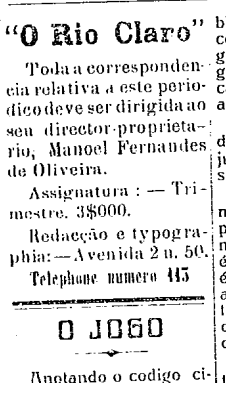 & 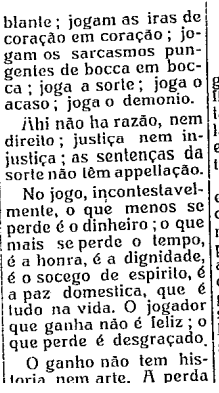 & 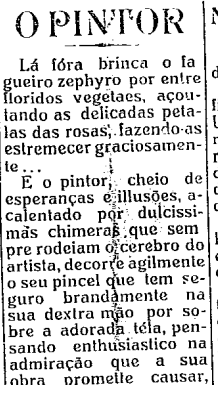 & 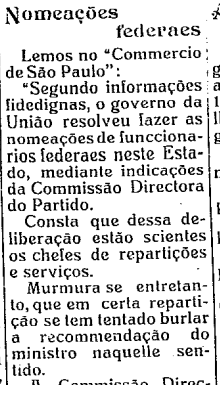 & 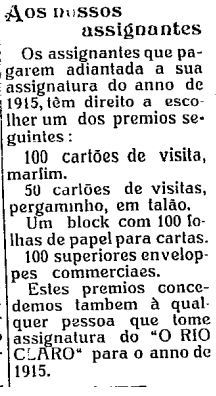 \\
\hline
\end{tabular}

Figura 4. O Rio Claro, exemplar de 3 de janeiro de 1915

A definição do recorte temporal se justifica pela relativa ausência de informações sobre o processo em estudo nesse período de tempo, que se situa no intervalo entre um processo inicial de variação e o estágio atual de predomínio da antes variante inovadora. Quanto às fontes documentais, acreditamos que, sendo um texto público, o texto jornalístico tanto atua sobre os componentes da situação sócio-histórica ao qual está vinculado, quanto sofre influências dessa situação. Essa dualidade faz dele uma fonte muito rica para se avaliar a expressão da norma (lingúística) prescritiva - socialmente prestigiada - e, ao mesmo tempo, detectar características inovadoras da(s) norma(s) objetiva(s), que, de tão presentes no uso, começam a ser incorporadas à escrita.

Além disso, o jornal constitui um hipergênero ou suporte textual, que comporta uma variedade de gêneros textuais (Bonini, 2003; Marcuschi, 2008). A concepção de gênero textual adotada é aquela estabelecida a partir de Bakhtin (1979), levando-se em conta seus desdobramentos e aplicações atuais (Bazerman, 2005; Fiorin, 2006; Marcuschi, 2008) - "gêneros são tipos de enunciados relativamente estáveis, caracterizados por um conteúdo temático, uma construção composicional e um estilo" (Fiorin, 2006, p. 61). Tal concepção, somada às discussões sobre gêneros nos jornais, presentes no trabalho de Bonini e em estudos da área de Comunicação (Lage, 2006; Reis, Zucco e Ramos, 2007, entre outros), servirá de base para uma análise que assume a heterogeneidade dos textos por meio dos quais (inter)agimos nas diferentes esferas de atividade humana. 


\section{Investigando as preposições nos jornais...}

Tendo estabelecido o quadro deste estudo, passemos à análise dos dados.

Partimos de duas questões principais:

1 - em que contextos 0 uso de para é, efetivamente, uma variante de a no período analisado?

2 - há diferenças detectáveis entre os vários gêneros textuais explorados?

Assim, dois aspectos principais são levados em conta na investigação: (i) fatores de natureza semântica, associados ao verbo e ao complemento e (ii) o gênero textual em que a construção ocorre (editorial, anúncio, nota social, notícia).

A análise de dados segue a metodologia variacionista, incluindo - levantamento de uma amostra representativa do fenômeno na tipologia de textos organizada, sua análise segundo os grupos de fatores definidos a partir das hipóteses, a quantificação dos dados analisados por meio de programas estatísticos (VARBRUL, GOLDVARB) e a interpretação dos resultados quantitativos à luz dos pressupostos teóricos que embasam o estudo (Weinreich, Labov, Herzog 1968; Labov 1972, 1994, 2001).

Se os resultados obtidos até o momento não são suficientes para chegarmos a uma resposta conclusiva às questões elencadas acima, começam a delinear um quadro para esse período. Foram analisados 604 dados em que as preposições a e para eram alternativas possíveis, colhidos nos quatro jornais selecionados. Os resultados indicam uma clara predominância da preposição a relativamente a para, o que já era esperado, dado o caráter normativo da primeira. Nos quatro jornais, a freqüência da preposição a oscila entre $71 \%$ e $87 \%$. 0 input geral de a, na análise multivariada, confirma a tendência: 0.782 .

A leitura "em negativo" desses índices, por outro lado, nos revela que existe uma margem de variação. Veremos que ela se diferencia, a depender das características semânticas do predicador e do complemento. A tabela 1, a seguir, apresenta os índices de emprego da preposição para (vs a) relativos ao tipo semântico do predicador verbal. 


\begin{tabular}{|l|c|c|c|c|}
\hline & Estado & Combate & Getulino & Rio Claro \\
\hline Direção & $31 \%$ & $30 \%$ & $34 \%$ & $14 \%$ \\
& $(16 / 51)$ & $(19 / 64)$ & $(25 / 73)$ & $(1 / 7)$ \\
\hline Mov./transf. & $64 \%$ & $8 \%$ & $30 \%$ & $50 \%$ \\
& $(14 / 22)$ & $(2 / 24)$ & $(8 / 27)$ & $(1 / 2)$ \\
\hline Transf.Mat. & $30 \%$ & $3 \%$ & $19 \%$ & $19 \%$ \\
& $(19 / 63)$ & $(2 / 65)$ & $(10 / 54)$ & $(5 / 26)$ \\
\hline Transf. & $0 \%$ & $3 \%$ & $13 \%$ & $6 \%$ \\
Verbal & $(0 / 33)$ & $(1 / 39)$ & $(3 / 23)$ & $(1 / 17)$ \\
\hline
\end{tabular}

Tabela 1. Frequência de uso da preposição para, segundo o tipo semântico do predicador verbal

Embora constatemos uma oscilação nos índices, de um jornal a outro, é possível identificar uma tendência que associa a maior presença da preposição inovadora a construções com predicadores de direção, de movimento com transferência e de transferência material e, inversamente, a manutenção por vezes categórica da preposição a com os predicadores de transferência verbal/perceptual.

U ma correlação mais clara emerge da análise da natureza semântica do complemento, tal como ilustra a figura $5^{1}$.

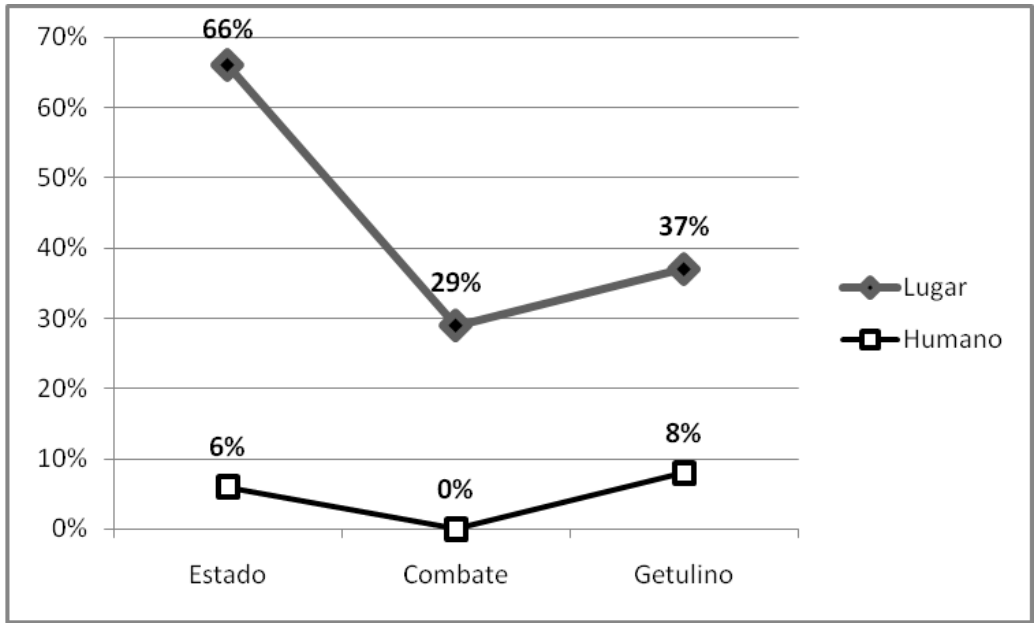

Figura 5. Frequência de uso da preposição para, segundo a natureza semântica do complemento

\footnotetext{
${ }^{1}$ Os índices de peso relativo reafirmam esse contraste: (i) complemento lugar. 0.755 (Estado), 0.535 (Combate), 0.770 (Getulino); (ii) complemento humano: 0.198 (Estado), 0.0 (Combate) e 0.193 (Getulino). Não obtivemos dados de tipo lugar em número significativo nos exemplares d' O Rio Claro.
} 
O bservamos que a preposição para tem seu espaço em construções que envolvem um complemento locativo. E que o uso dessa preposição junto a complementos com referente humano é, ainda, incipiente.

Além desses dois tipos de complemento, também se vê resistência ao uso de para com complementos que veiculam uma noção abstrata, caso ilustrado em (9). Em construções com essas características, o emprego dessa preposição não ultrapassa 10\% nos dados do Getulino e é inexistente n'O Estado e n'O Combate.

(9) a. (...) por me haver guiado ao caminho acertadissimo de usar as Pilulas Antidyspepeticas do dr. 0. Heinzelmann, para minha cura.)) ( O Estado de São Paulo, 02 / 01/1920, Anúncio)

b. (...) que optimos serviços tem prestado já á moralidade social de nossa terra. (Getulino, 30/12/1923, Nota)

A conjugação dos resultados dos dois grupos de fatores - tipo semântico do predicador verbal e natureza semântica do complemento — nos permite identificar os contextos em que os redatores dos jornais estão empregando a preposição para e chegar a uma caracterização da variação nesse período. É 0 que podemos observar pelos índices apresentados na tabela $2^{2}$.

\begin{tabular}{|l|c|c|}
\hline & Locativo & Humano \\
\hline Direção & $39 \%$ & $10 \%$ \\
& $(49 / 127)$ & $(1 / 10)$ \\
\hline Mov./transf. & $41 \%$ & $0 \%$ \\
& $(18 / 44)$ & $(0 / 3)$ \\
\hline Transf.Mat. & $62 \%$ & $3 \%$ \\
& $(26 / 42)$ & $(4 / 120)$ \\
\hline Transf. Verbal & - & $5 \%$ \\
& & $(4 / 86)$ \\
\hline
\end{tabular}

Tabela 2. Frequência de uso da preposição para, segundo o tipo semântico do predicador verbal e a natureza semântica do complemento

Os resultados da análise quantitativa nos levam à identificação de duas configurações diferentes no emprego das preposições:

${ }^{2}$ Os resultados referem-se ao conjunto dos dados dos quatro jornais analisados. 0 amálgama sintetiza uma correlação observada independentemente para cada um dos periódicos. 
(I) Convivência/concorrência das preposições em contexto de complemento [locativo] (o que poderíamos chamar de variação propriamente dita) $(10-12)$ :

(10) a. Feitas as apresentações de estylo, foram as senhoras conduzidas em automoveis para a residência do snr. Brasilio Pereira. (Getulino $30 / 12 / 1923$, Nota)

b. Os cavalheiros tomando outros automoveis, foram conduzidos ao centro da cidade. (Getulino, 30/12/1923, Nota)

(11) a. No dia seguinte, todos os operarios se dirigiram para a fabrica, ficando estupefatos ao depararem com um aviso [...]. ( 0 Combate, 02/03/1918, Nota)

b. Terminado que foi, a commisão campineira, acompanhada de senhorias, senhoras e cavalheiros, dirigiram-se para a sede social da Elite Flor da Liberdade (Getulino, 06/01/1924, Nota)

c. Acto continuo, dirigiu-se ao escritório do Crespi uma dessas victimas (...). ( O Combate, $02 / 03 / 1918$, Nota)

(12) a. Chegados a São Paulo, em uma manhã, foram logo levados para um casarão em uma rua deserta (Getulino, 23/12/1923)

b. [...] que quando na idade de sete annos, meu pae me levou á escola, eu já amava a minha Patria, respeitava a minha bandeira, sabia o nome dos meus gloriosos antepassados, [...] (Getulino, 9;9 1923 - editorial)

Observe-se que as construções trazem, exatamente, as características sintático-semânticas que apontamos como as que se associam com o uso de para. O u seja, é quando se expressa um movimento físico, concreto, em direção de uma meta que denota um lugar concreto que se dá a possibilidade de escolha entre a e para. Esse representa, do ponto de vista estrutural, o contexto de entrada da variação.

(II) Predomínio da preposição a com complementos [animado/humano] (13)

(13) a. 0 pleito de hontem deve trazer aos verdadeiros patriotas a convicção de que é preciso continuar a resistencia por todos os meios [...] (O Combate, p. 13, 02/03/1918 - Nota).

b. 0 sr. Noé Juliao, residente actualmente em Socorro, onde gosa de geral estima, e que aqui esteve largos annos, como que querendo "matar" as saudades da "excelsa campinéa" onde seu nome de cidadão probo é recordado com affeição, enviou ao nosso chefe a seguinte 
carta: (Getulino, 26/8/1923 - editorial)

c. Da casa do sapateiro, o expertalhão escreveu uma carta a Luciano Vicentino, residente á rua Monsenhor Andrade pedindo a este para entregar ao portador, o proprietario dos saccos, a importancia de 185 mil réis. (O Combate, 02/03/1918, Nota).

d. Eu só pergunto ao collega sr. Dyonisio se a esomola resolve 0 problema do professorado bahiano [...]. ( O Combate, 01/04/1918, Nota).

e. (...) 0 declarante narrou taes segredos por escripto a differentes pessoas (...). ( 0 Combate, 01/06/1918, Nota).

Na situação descrita em (II), é preciso distinguir os contextos segundo o tipo de predicador: (i) os predicadores de movimento com transferência (13a) e transferência material (13b) também podem ocorrer com complemento locativo, que pode ser introduzido pela preposição para, como vimos em (I). Nesse caso, estabelece-se um certo tipo de 'distribuição complementar' no uso da preposição dependendo da natureza do complemento que acompanha o verbo; (ii) com os predicadores de transferência verbal/perceptual (13 c-e) não há a opção de um complemento locativo, e o emprego de a é quase categórico.

No quadro acima esboçado, a natureza semântica do complemento desponta como o fator de mais peso na definição da variação. Isso fica patente no fato de ter sido o único grupo de fatores selecionado em todas as rodadas de análise multivariacional realizadas (ao contrário do tipo de predicador, que foi sistematicamente não-selecionado). Os índices obtidos falam por si:

\begin{tabular}{|l|c|c|}
\hline & A & PARA \\
\hline Locativo & 0.169 & 0.831 \\
\hline Humano & 0.807 & 0.193 \\
\hline
\end{tabular}

Tabela 3. Indíces de peso relativo, segundo a natureza semântica do complemento

Paralelamente a essas duas configurações bem definidas, identificamos alguns poucos casos em que se percebe o avanço do uso inovador. Trata-se do emprego de para em contexto de complemento humano (14) ou complemento que se refere a uma noção abstrata (15): 
(14 )a. [...] appareceu uma das mais graciosas vendedoras que se dirigindo para ele disse: 'compre uma prenda para essa mocinha.'

(Getulino, 20/01/1924, Nota)

b. Ahi está a razão dos ápodos que em conúbio de escribas nos são atirados, mas que felismente não nos attingem e tão pouco engraquessem a nossa Penna, que sempre prompta é para causticar os devassadores da classe mostrando para aquelles que innocentemente reincidem em erro, apezar de não serem passíveis de culpa, o verdadeiro cul [...inint...] (Getulino, 2/9/1923, Editorial) c. Enviamos para á distincta preceptora os nosso parabens pelo adiantamento de suas alumnas [...]. (O Estado de São Paulo, 03/01/ 1910 - Os Municípios - Nota)

(15) a. Isso tanto os que se dedicam habitualmente á cultura algodoeira como os que para ella appellaram como um lenitivo á desgraça da geada" (Combate, 1918, Editorial))

b. E quantos descendentes dessa raça malsinada, levantando-se da condição miseravel em surtos sublimados, alaram-se aos cimos onde se reunem em choréa as musas e de lá troxeram para a nossa história laureas immarcessiveis". (Getulino,1923 Editorial)

Embora em número limitado, essas ocorrências apontam no sentido do caminho que o processo irá tomar, se levarmos em conta as conclusões dos estudos sobre estágios atuais do PB, já mencionados, particularmente em sua modalidade falada.

No que se refere ao nosso segundo questionamento, relativo a uma possível correlação entre o gênero textual em que ocorreu a construção e a variação entre a e para, nossa análise conduziu a mais perguntas que respostas. Os dados investigados provieram de textos dos gêneros editorial, nota, anúncio e notícia. Em termos de índices gerais, não se desenhou uma hierarquia clara entre os gêneros: a preposição para está presente em $25 \%$ dos dados dos anúncios, em 20,5\% dos dados dos editoriais, em $23 \%$ dos dados das notas e $15 \%$ dos dados das notícias. 0 grupo de fatores não foi selecionado como relevante para a explicação da variação, e os quatro jornais apresentaram quadros diferentes: enquanto no Getulino e n'O Rio Claro, os editoriais reúnem uma presença maior da preposição para que as notas, verifica-se 0 inverso n' $O$ Estado, e n' $O$ Combate há índices equivalentes nos dois gêneros. As notícias parecem constituir um gênero mais permeável à variante inovadora n'O Estado $(29,5 \%$ de para), mas se mostram um contexto de resistência n'O Combate (17\% de para). 
Considerando, no caso em estudo, que a variação aparece fortemente associada a características de natureza linguística, restringimos a avaliação do papel dos gêneros ao contexto identificado como o mais favorável à presença da preposição para - as construções com complemento locativo. Apesar de tal recorte levar a células com um número por vezes pequeno de dados, emerge daí um indício de hierarquia que merece ser investigado com maior profundidade. É o que vemos na tabela 4.

\begin{tabular}{|c|c|c|c|}
\hline Anúncios & Editorial & Notas & Notícias \\
\hline $73 \%$ & $41 \%$ & $40 \%$ & $31 \%$ \\
$(24 / 33)$ & $(18 / 44)$ & $(45 / 113)$ & $(8 / 26)$ \\
\hline 0.991 & 0.771 & 0.771 & 0.485 \\
\hline
\end{tabular}

Tabela 4. Frequência e peso relativo - preposição para em construções com complementos locativos.

\section{0 que esses dados sincrônicos permitem dizer sobre mudança...}

Tomamos como moldura do momento analisado, por um lado, a baixa freqüência ou quase ausência da preposição para nos contextos aqui considerados, tal como observada em estudos referentes aos séculos XVIII e XIX (Berlinck, 2000, 2001; Guedes e Berlinck, 2003)3 e, por outro, a predominância do emprego dessa preposição nos estágios atuais do PB (Berlinck, 1998; Gomes, 2003; Mollica, 1996; Torres-Morais, Berlinck, 2006).

Os estudos de Berlinck $(2000,2001)$ mostram que, até o final do século XIX, o emprego geral de para não ultrapassava 10,5\% nos contextos em análise. 0 locus desse uso estava nas construções com predicadores de direção e de transferência material (12\% e $23 \%$ de para, respectivamente), em dados de anúncios de jornais. Por outro lado, as últimas décadas do século XX revelam o predomínio da preposição para. É o que constatam, por exemplo, Gomes (2003), para a fala carioca (88\% com verbos do tipo de dar e $84 \%$ com verbos do tipo de falar) e Berlinck (2000) para a fala curitibana ( $93 \%$ de para com complementos dativos de $3^{\mathrm{a}}$ pessoa).

A partir disso e dos resultados obtidos no presente estudo, é possível considerar que o percurso do processo de substituição de a por

\footnotetext{
${ }^{3}$ Os estudos referentes aos séculos XVIII e XIX analisaram dados provindos de relatos de viagem, peças de teatro e anúncios de jornais. Aqueles que focalizaram os estágios atuais do PB analisaram amostras de língua falada ou de língua escrita (anúncios e cartas de leitores/redatores).
} 
para atende a um dos princípios gerais dos processos de gramaticalização - de que a mudança se dá do concreto para o abstrato (Neves, 1997, p. 131). 0 u seja, ela se inicia em contextos que exprimem situações concretas (predicadores que exprimem movimentos físicos, que têm como meta lugares concretos):

(i) passa a situações em que se denota um movimento físico, mas em que a meta se transmuta num destinatário humano. Isso implicaria em um grau maior de abstração, porque associa ao movimento uma idéia de transmissão de posse;

(ii) atinge contextos em que a combinação dos argumentos do predicador leva a uma interpretação abstrata de movimento, tendo um 'objeto' abstrato a ser transferido e / ou uma meta abstrata a ser alcançada.

Quando investigamos o processo em um de seus estágios intermediários, como é o caso no presente estudo, verificamos que os usos inovadores estão proporcionalmente mais presentes nos contextos que envolvem predicadores de direção, de movimento com transferência e de transferência material, quand o o complemento se refere a um Iugar concreto, caso descrito em (i). Nesse sentido, concluímos que nem todas as distinções consideradas em termos de uma tipologia de predicadores verbais se mostraram relevantes para a caracterização da variação entre as preposições estudadas nesse período, o que fica patente pelo fato de esse grupo de fatores não ter sido selecionado na análise multivariacional.

Complementarmente, identificamos alguns casos que correspondem aos estágios em (ii) e em (iii), indicando que já se manifestava, ainda que timidamente, uma tendência que vai se consolidar nos estágios atuais do PB.

Estamos diante de um processo em que uma preposição já presente na língua (para) começa a assumir funções e a ocupar contextos de uso antes exclusivos da preposição a. Nesse sentido, consideramos ser possível descrever esse processo como um tipo de gramaticalização de para, na medida em que tem expandida a sua funcionalidade na língua.

Por fim, considerando a segunda questão que guia este estudo, observou-se que o gênero textual não apresenta nesta amostra um papel decisivo nas escolhas dos falantes. Ressalte-se que uma grande dificuldade encontrada na aplicação dessa abordagem está ligada à própria identificação dos gêneros nos jornais da época. Berlinck e Bueno (2008) já advertem que "os textos nem sempre se deixam 'classificar' facilmente", e isso se dá, em boa parte, porque, como afirma Bulhões (2007), o fim do $X I X$ e 0 início do XX "não foi marcado por uma delimitação rigorosa 
entre os gêneros jornalísticos, algo que se vai desenvolver no Brasil a partir da década de 1950, (...)".

Embora consideremos imprescindível levar em conta a heterogeneidade dos gêneros e a possibilidade de que as variantes circulem de um modo diferente em cada um deles, admitimos que é preciso aprofundar a avaliação das características dos gêneros que são relevantes para 0 estabelecimento de uma escala pela qual possamos ordená-Ios - sejam aspectos do conteúdo temático ou do estilo seja uma combinação de aspectos dessas duas propriedades. Fica claro que tal escala precisa ser definida de modo independente em relação ao fenômeno estudado.

Apesar do desafio que essa perspectiva representa, reiteramos a convicção de que é fundamental investir no estabelecimento de critérios e parâmetros consistentes para a distinção dos textos segundo os gêneros que materializam e a incorporação desses fatores na análise de fenômenos lingüísticos.

Uma outra linha de interpretação que nos parece merecer investigação vem do tipo de fenômeno variável que está sendo investigado, do ponto de vista de sua avaliação social. Embora a norma gramatical apresente a preposição a como típica dos contextos estudados, não há uma cobrança explícita quanto ao seu emprego. 0 que queremos dizer é que, ao contrário de fenômenos como a marcação de número no sintagma nominal e no sintagma verbal, ou a expressão anafórica do objeto direto por um clítico acusativo, a variação de preposições não está sujeita a uma forte avaliação social. De modo que as alternâncias e a gradativa substituição da preposição a por para (em menor intensidade, também por em e até) nos contextos dos predicadores analisados não sofrem fortes pressões externas e têm, por isso, condições favoráveis para se expandir. As conclusões dos estudos sobre o estágio atual da variedade brasileira parecem confirmar esse percurso.

\section{Referências Bibliográficas}

BAKHTIN, M. Estética da criação verbal. São Paulo: Martins Fontes, 1992.[1979]

BAZERMAN, C. Gêneros textuais, tipificação e interação. Angela Paiva Dionísio, Judith Chambliss Hoffnagel (orgs). São Paulo: Cortez, 2005.

BERLINCK, R. de A. "The Portuguese Dative". In W. Van Belle \& W. Van Langendonck (orgs.). Case and Grammatical Relations Across Languages. The 
Dative. Vol. I: Descriptive Studies. Amsterdam/Philadelphia: John Benjamins, 1996. pp. 119-151.

. Sobre a realização do objeto indireto no português do Brasil. In: ENCONTRO DO CÍRCULO DE ESTUDOS LINGUÍSTICOS DO SUL CelSul, n. 2, 1997, Florianópolis. Anais... Florianópolis: UFSC, 1997.

. Relatório final do Projeto 'O objeto indireto no português do Brasil' (CNPq). 1998.

. O objeto indireto no português brasileiro do século XIX. In: CONGRESSO NACIONAL DA ABRALIN, n. 2, 2000, Florianópolis. Anais... Florianópolis: UFSC, 2000.

. "Dativo ou Locativo? Sobre sentidos e formas do 'dativo' no português". Revista Letras 56. pp.159-175. (Publicação do Curso de Letras da UFPR). 2001.

- Relatório final do Projeto 'Preposições no português quinhentista do Brasil. 2006.

. "Crônicas \& relatos de viagem: fontes para o estudo da história da língua". In: MURAKAWA, C. de A.A.; GO N ÇALVES, M.F. (orgs.). Novas contribuições para o estudo da história e da historiografia da língua portuguesa (Séire Trilhas Linguísticas,11). Araraquara: Laboratório Editorial FCL?UNESP; São Paulo: Cultura Acadêmica, 2007.

BERLINCK, R. de A.; BUEN 0, L.C. de 0. Variação e gênero textual: preposições em textos jornalísticos paulistas. In: CONGRESSO INTERNACIONAL DA ASSOCIAÇÃO DE LINGUÍSTICA E FILOLOGIA DA AMÉRICA LATINA (ALFAL), n. 15, 2008, Montevidéu. Resumos... Montevidéu: Universidad de la Republica, 2008.

BONINI, A. "Os gêneros do jornal: o que aponta a literatura da área de comunicação no Brasil?" Linguagem em (Dis)curso, Tubarão/SC, v. 4, n. 1, pp. 205-231, jul. / dez. 2003.

BULHÕES, M. "João do Rio e os gêneros jornalísticos no início do século XX". Revista Famecos, n³2, pp.78-84. Porto Alegre, 2007.

CASTILHO, A. T. de et al. Gramaticalização de algumas preposições no português brasileiro do séc. XIX. Comunicação apresentada no V Seminário do PHPB (Projeto Para a História do Português Brasileiro), 0 uro Preto $M G, 2002$.

DOMINGUES, P. Consciência de cor. Revista de História da Biblioteca 
Nacional, nº.11, pp. 64-68, 2006.

FERRARA, M.N. A imprensa negra paulista (1915 - 1963). FFLCH / USP, 1986. (Antropologia 13).

FIORIN, J. L. Introdução ao pensamento de Bakhtin. São Paulo: Ática, 2006. GOMES, C. A. "Variação e mudança na expressão do dativo no português brasileiro". In: PAIVA, M. da C.; DUARTE, M.E.L. (orgs.). Mudança lingüística em tempo real. Rio de Janeiro: Contra Capa Editorial, 2003.

GOMES, V. S. "História do editorial jornalístico em Pernambuco: o que mudou e o que permaneceu no curso desta tradição discursiva?" In: PESSOA, M. de B. (org.). Língua, textos e história: manuscritos e impressos na história do português brasileiro. Recife: Programa de Pós-Graduação da UFPE, 2005. pp. 87-107.

GUEDES, M., BERLINCK, R. de A. "Variação em complementos preposicionados no português paulista do século XIX.." Estudos Lingüísticos 32. Documento C198.htm. Publicação do Grupo de Estudos Lingüísticos do Estado de São Paulo. 2003.

LAB OV, W. Sociolinguistic patterns. Philadelphia: University of Pennsylvania Press, 1972.

LABOV, W. Principles of Linguistic Change. Vol. 1: Internal Factors. Cambridge, MA / Oxford: Blackwell Publishers, 1994.

LABOV, W. Principles of Linguistic Change. Vol. 2: Social Factors. Cambridge, MA / Oxford: Blackwell Publishers, 2001.

LAGE, N. Estrutura da notícia. São Paulo: Editora Ática, 2006. (Série Princípios)

MARC USCHI, L. A. Produção textual, análise de gêneros e compreensão. São Paulo: Parábola Editorial, 2008.

MOLLICA,M.C. de M. "A regência variável do verbo ir de movimento". In O LIVEIRA e SILVA,G., SC HERRE, M.M.P.(orgs.). Padrões Sociolingüísticos. Rio de Janeiro: Tempo Brasileiro, 1996.

NEVES, M. H. de M. A Gramática funcional. São Paulo: Martins Fontes, 1997.

REIS, C.; ZUCC 0, F. D; RAMOS, P. Os gêneros jornalísticos nas emissoras de rádio de Blumenau. In: CONGRESSO BRASILEIRO DE CIÊNCIAS DA C OMUNICAÇÃ 0, n. 30, 2007, Santos. Anais... Disponível em: http:/ 
/ www.intercom.org.br / papers / nacionais / 2007 / resumos / R0792-1.pdf. Acesso em: 12 março. 2011.

TARALLO, F. L. Relativization Strategies in Brazilian Portuguese. Tese (Doutorado em Linguística) - University of Pennsylvania, Philadelphia, 1983.

TORRES-M ORAIS, M. A. C. R.; BERLINCK, R. de A. "A caracterização do objeto indireto no português: aspectos sincrônicos e diacrônicos". In: LOB O, T. et al. (orgs.). Para a história do português brasileiro. Vol. VI: Novos dados, novas análises. Tomo I. Salvador: EDUFBA, 2006. pp. 73-105.

WEINREICH, U., LABOV, W. \& HERZOG, M. "Empirical Foundations for a Theory of Language Change". In W.P. Lehmann \& Y. Malkiel (orgs.). Directions for Historical Linguistics. Austin: University of Texas Press, 1968. 


\section{Resumo}

0 presente estudo focaliza a variação no uso de preposições em contextos de complementação verbal em textos jornalísticos publicados nas primeiras décadas do século XX em jornais paulistas. 0 objetivo principal é caracterizar tal variação em um momento que se situa a meio caminho entre um estágio de predomínio quase absoluto da preposição a (primeira metade do século $X I X)$ e um quadro em que se destaca a preposição para como a variante dominante (fim do século $X X$ ). Dois aspectos principais são levados em conta na análise: (i) fatores de natureza semântica, associados ao verbo e ao complemento e (ii) o gênero textual em que a construção ocorre (editorial, anúncio, nota social, notícia). A análise de dados segue a proposta teóricometodológica da Teoria da Variação e Mudança Linguísticas (Weinreich, Labov, Herzog, 1968; Labov, 1972, 1994, 2001) e adota a concepção de gênero textual, tal como estabelecida a partir de Bakhtin (1979) e outros desdobramentos e aplicações atuais (Bazerman, 2005; Fiorin, 2006; Marcuschi 2008), além das discussões sobre gêneros nos jornais, presentes no trabalho de Bonini (2003) e em estudos da área de Comunicação. Os resultados revelam um quadro heterogêneo que inclui contextos efetivamente variáveis (em que se expressa um movimento físico, concreto, em direção de uma meta que denota um lugar concreto) e contextos quase impermeáveis à variante inovadora (complementos que denotam um referente humano e predicadores de transferência verbal/perceptual).

Palavras-chave: preposição, complementação verbal, gênero textual, variação linguística, português brasileiro

\section{Abstract}

This study analyses the variable use of prepositions (particularly $a$ and para) as verb complement in newspaper articles published in the early decades of the 20th century in São Paulo newspapers. The purpose is to investigate such variation in a moment that lies 
half way between a stage of almost complete dominance of the preposition a (the first half of the 19th century) and the appearance of preposition para, which would become the dominant variant in the end of the 20th century). Two main aspects are taken into account in the analysis: (i) semantic factors, associated with the verb and its complement and (ii) the genre in which the construction occurs (editorials, advertisements, social notes, news). Data analysis follows the theoreticalmethodological proposal of the Theory of Language Variation and Change (Weinreich, Labov, Herzog, 1918, Labov, 1972, 1994, 2001) and adopts the concept of genre, as established in Bakhtin (1979). Other developments and current applications (Bazerman, 2005; Fiorin, 2006; Marcuschi, 2008), as well as discussions on gender in newspapers, as present in the work of Bonini (2003) and studies in the area of Communication are also taken into account. The results show a mixed picture including contexts effectively variable (which express a physical concrete movement, towards a goal that denotes a specific place) and contexts almost impermeable to the innovative variant (complements that show a human referent, predicators of verbal or perceptual transfer).

Keywords: preposition, verbal complementation, genre, linguistic variation, Brazilian Portuguese 